\title{
Mutation Analysis in Nephronophthisis Using a Combined Approach of Homozygosity Mapping, CEL I Endonuclease Cleavage, and Direct Sequencing
}

\author{
Edgar A. Otto, ${ }^{1}$ Juliana Helou, ${ }^{1}$ Susan J. Allen, ${ }^{1}$ John F. O’Toole, ${ }^{1}$ Eric L. Wise, ${ }^{1}$ Shazia Ashraf, ${ }^{1}$ \\ Massimo Attanasio, ${ }^{1}$ Weibin Zhou, ${ }^{1}$ Matthias T.F. Wolf, ${ }^{1}$ and Friedhelm Hildebrandt ${ }^{1,2 *}$ \\ ${ }^{1}$ Department of Pediatrics, University of Michigan, Ann Arbor, Michigan; ${ }^{2}$ Human Genetics, University of Michigan, Ann Arbor, Michigan \\ Communicated by Peter Byers
}

Nephronophthisis (NPHP), an autosomal recessive kidney disease, is the most frequent genetic cause of chronic renal failure in the first three decades of life. Mutations in eight genes (NPHP1-8) have been identified. We here describe a combined approach for mutation screening of NPHP1, NPHP2, NPHP3, NPHP4, and NPHP5 in a worldwide cohort of 470 unrelated patients with NPHP. First, homozygous NPHP1 deletions were detected in 97 patients $(21 \%)$ by multiplex PCR. Second, 25 patients with infantile NPHP were screened for mutations in inversin (NPHP2/INVS). We detected a novel compound heterozygous frameshift mutation (p. [Q485fs] $+[\mathrm{R} 687 \mathrm{fs}])$, and a homozygous nonsense mutation (p.R899X). Third, 37 patients presenting with NPHP and retinitis pigmentosa (Senior-L $\varnothing$ ken syndrome [SLS]) were screened for NPHP5/ IQCB1 mutations by direct sequencing. We discovered five different (three novel) homozygous premature termination codon (PTC) mutations (p.F142fsX; p.R461X; p.R489X; p.W444X; and c.488-1G > A). The remaining 366 patients were further investigated for mutations in NPHP1, NPHP3, and NPHP4. We applied a "homozygosity only" strategy and typed three highly polymorphic microsatellite markers at the respective loci. A total of 32, eight, and 14 patients showed homozygosity, and were screened by heteroduplex crude celery extract (CEL I) endonuclease digests. The sensitivity of CEL I was established as $92 \%$, as it detected 73 out of 79 different known mutations simply on agarose gels. A total of 10 novel PTC mutations were found in NPHP1 (p.P186fs, p.R347X, p.V492fs, p.Y509X, and c.1884+1G >A), in NPHP3 (c.3812+2T >C and p.R1259X), and in NPHP4 (p.R59X, p.T1004fs, and p.V1091fs). The combined homozygosity mapping and CEL I endonuclease mutation analysis approach allowed us to identify rare mutations in a large cohort of patients at low cost. Hum Mutat 29(3), 418-426, $2008 . \quad$ (c) 2007 Wiley-Liss, Inc.

KEY WORDS: nephronophthisis; Senior-Løken syndrome; mutation detection; CEL I endonuclease; NPHP1; NPHP2/ INVS; NPHP3; NPHP4; NPHP5/IQCB1; homozygosity mapping

\section{INTRODUCTION}

Nephronophthisis (NPHP) is a rare autosomal recessive kidney disease, which leads to progressive renal failure in children and adolescents. NPHP is the most frequent genetic cause for endstage renal failure (ESRF) in the first three decades of life. On kidney histology tubular basement membrane disintegration, fibrosis, and cyst formation at the corticomedullary border are the prominent features. About $15 \%$ of all patients develop retinitis pigmentosa (Senior-Løken syndrome [SLS]). Other extrarenal symptoms have been described, in particular oculomotor apraxia (type Cogan), cerebellar ataxia (Joubert syndrome), mental retardation, liver fibrosis, and bone anomalies. To date, eight causative genes, NPHP1-8 (MIM\#s 256100, 602088, 604387, 606966, 609237, 610142, 608539, and 610937) have been identified by positional cloning [Hildebrandt et al., 1997; Otto et al., 2002, 2003, 2005; Mollet et al., 2002; Olbrich et al., 2003; Sayer et al., 2006; Attanasio et al., 2007; Delous et al., 2007]. Recently, functions of primary cilia, basal bodies, and centrosomes have been implicated in the pathogenesis of NPHP [Hildebrandt and Otto, 2005].

With the exception of NPHP1, only a few mutations for each gene have been described. NPHP1 is the gene most frequently

The Supplementary Material referred to in this article can be accessed at http://www.interscience.wiley.com/jpages/1059-7794/ suppmat.

Received 5 March 2007; accepted revised manuscript 18 September 2007.

Grant sponsor: National Institutes of Health; Grant numbers: DK069274; DK068306; and DK064614; Grant sponsor: National Kidney Foundation (NKF); Grant number: N004727.

*Correspondence to: Friedhelm Hildebrandt, M.D., University of Michigan Health System, 8220C MSRB III, 1150 West Medical Center Drive, Ann Arbor, MI. E-mail: fhilde@umich.edu

DOI 10.1002/humu.20669

Published online 12 December 2007 in Wiley InterScience (www. interscience.wiley.com). 
mutated in NPHP due to unequal recombination events between two 45-kb direct flanking repeats, leading to a large 290-kb deletion [Saunier et al., 2000]. Additionally, a rare smaller NPHP1 deletion of $151 \mathrm{~kb}$ with defined breakpoints was described [Otto et al., 2000]. Mutations in the other NPHP genes account only for 1 to $3 \%$ each. Recently we demonstrated that inversin, a protein involved in left-right patterning in vertebrate embryos is mutated in patients with infantile NPHP (NPHP type 2) who develop early onset ESRF. To date, we detected inversin (NPHP2/INVS) mutations only in 10 patients from eight families worldwide [Otto et al., 2003; O'Toole et al., 2006]. In NPHP type 3, only nine patients were described so far, and in only three of these both alleles were found to be mutated [Olbrich et al., 2003]. For the NPHP4 gene, mutations in both alleles have been reported in 17 patients altogether [Mollet et al., 2002; Otto et al., 2002; Hoefele et al., 2005]. Recently, we identified NPHP5/IQCB1 as a fifth causative gene mutated in NPHP [Otto et al., 2005]. Recessive premature termination codon (PTC) mutations were found in 16 patients. All patients had the association of early onset retinitis pigmentosa and are therefore considered SLS. Saunier et al. [2005] reported seven additional patients with NPHP5 mutations in a small cohort of 13 early-onset SLS patients. Very recently, we identified a novel centrosomal protein NPHP6/CEP290, which is mutated in patients with NPHP type 6 [Sayer et al., 2006]. All patients carried recessive PTC mutations and the association of cerebellar vermis aplasia, mental retardation, and early-onset retinitis pigmentosa (Joubert syndrome; JBTS5) with the exception of one patient who presented with NPHP and retinitis pigmentosa only. Another rare cause for NPHP (NPHP type 7) are mutations in the transcription factor GLIS2, leading to increased apoptosis in humans and in mice [Attanasio et al., 2007]. Recently, mutations in the gene encoding the ciliary protein RPGRIP1L have been identified in patients with Joubert syndrome and associated NPHP (JBTS6) and in patients with Meckel syndrome, a lethal disease with overlapping clinical features [Delous et al., 2007].

Over the last 15 years we ascertained worldwide DNA samples from 730 unrelated patients with NPHP, of which 470 have not been analyzed for mutations in the known genes NPHP1-5. Mutations in NPHP6/CEP290 [Sayer et al., 2006] and NPHP7/ GLIS2 [Attanasio et al., 2007] we published recently. Mutation screening was performed by using a combination of multiplex-PCR deletion analysis, direct sequencing, homozygosity mapping, and crude celery extract (CEL I) endonuclease mutational analysis (see flow diagram in Fig. 1 for details). Besides many homozygous NPHP1 deletions, we identified recessive mutations in 24 patients demonstrating that the combined approach is effective to find rare mutations and this approach enabled us to identify many novel mutations in the NPHP1-5 genes in a large cohort of patients.

\section{Human Subjects}

\section{MATERIALS AND METHODS}

We obtained blood samples, pedigrees, and clinical information after receiving informed consent (www.renalgenes.org) from 470 patients with NPHP with or without extrarenal manifestations and/or their parents. This cohort of 470 unrelated patients consists of 372 (79\%) patients with isolated NPHP, 71 (15\%) patients with NPHP associated with retinitis pigmentosa (SLS), 21 (4.5\%) patients with Cogan oculomotor apraxia, three $(0.6 \%)$ patients with liver fibrosis, and three $(0.6 \%)$ with bone malformations. The cohort consists of 72 (15\%) familial cases vs. 398 sporadic cases. Consanguinity was known to be present in 38 (8\%) families. The diagnosis of NPHP was confirmed in 137 (29\%) patients by a renal



FIGURE 1. Flow diagram illustrating the stepwise combined approach for mutation screening of NPHP1, -2, -3, -4, and -5 in a cohort of 470 patients with NPHP. The number of patients in whom recessive mutations in the respective gene were found is indicated in gray boxes. Initially all patients were screened for homozygous NPHP1 deletions. DNA samples of patients presenting with end stage renal failure (ESRF) $\leq 5$ years were screened for mutations in inversin (NPHP2/INVS), and samples of patients with NPHP and retinitis pigmentosa (SLS) were analyzed for mutations in NPHP5/IQCB1 by direct sequencing. Remaining patients were screened for "homozygosity only" at the respective loci of NPHP1, -3, and -4 by genotyping three polymorphic microsatellite markers each. Marker positions are indicated in relation to the respective NPHP genes on chromosome 2,3 , and 1 , respectively, according to the data of the 2006 freeze of the University of California Santa Cruz (UCSC) genome browser. Patients homozygous for the respective markers were further analyzed. Mutation analysis was performed by heteroduplex CEL I endonuclease digests of all exon-PCR products of the respective NPHP genes. PCR products showing an aberrant banding pattern on agarose gels after electrophoresis were sequenced to identify the underlying mutations (gray boxes). 
biopsy. A total of 25 patients presented with ESRF at age 5 years or below, of whom six patients showed a situs inversus phenotype. In 34 out of the 71 patients who presented with SLS, NPHP5/IQCB1 sequence analysis was performed earlier [Otto et al., 2003]. Patients with NPHP and additional cerebellar malformations (Joubert syndrome) were not enrolled in this study. Approval for experiments on humans was obtained from the University of Michigan Institutional Review Board. In all patients the diagnosis NPHP was based on the following criteria: 1) clinical course with characteristic clinical signs of chronic renal failure, polyuria, polydipsia, anemia, and growth retardation; 2) renal ultrasound or renal biopsy compatible with the diagnosis of NPHP as judged by a (pediatric) nephrologist; and 3) pedigree compatible with autosomal recessive inheritance.

\section{NPHP1 Deletion Analysis}

As a first diagnostic step, we screened genomic DNA of 470 patients with NPHP for the presence of homozygous NPHP1 deletions. We applied a multiplex PCR approach, which we have modified compared to a procedure published earlier [Hildebrandt et al., 2001]. Three markers within the common NPHP1 deletion and two control markers were amplified in a single PCR reaction as shown in Fig. 2A. Primer sequences and PCR conditions are available from the authors.

\section{Microsatellite Homozygosity Mapping}

In order to search for homozygosity at the NPHP1, NPHP3, and NPHP4 loci, we genotyped one affected individual of each of 366 families with NPHP using three microsatellite markers within each gene region. For NPHP1 we used three formerly published polymorphic microsatellite markers localized within the $290-\mathrm{kb}$ deleted NPHP1 region. Only two out of these markers localize within the rare smaller $151 \mathrm{~kb}$ NPHP1 deleted region [Otto et al., 2000]. Microsatellite markers del-16, del5-5(2), and del-10 were amplified with the following forward $(\mathrm{F})$ and reverse $(\mathrm{R})$ primers: del-16_F, 5'-GCAAATTGCAATGGGAAGG-3'; del-16_R, 5' CTCAGTCTGGCAATGAATCC-3'; del-5-5(2)_F, 5'-CCTGAT CTGGAGAAGTAGGT-3', del-5-5(2)_R, 5'-ACAATGAATGGG TCTCAAGC-3'; del-10_F, 5'-GCTGTGCATCTCTTCTGACT-3'; and del-10_R, 5'-AGGTACCTGGAACTCTGAGA-3'. The heterozygosity indices were 0.56 [del-16], 0.54 [del-5-5(2)], and 0.41 [del-10], respectively. The probability that all three markers at the NPHP1 locus are homozygous by chance, calculated simply by multiplying all three homozygosity indices, is one in nine cases (12\%). For homozygosity screening within the NPHP3 region, markers D3S1273, D3S1290, and D3S3713 were used, with heterozygosity indices of $0.8,0.86$, and 0.92 , respectively. The probability of these markers at the NPHP3 locus being homozygous by chance is one in 417 cases $(0.24 \%)$, assuming linkage equilibrium for these markers. NPHP4 locus screening was performed with markers D1S2633, D1S2870, and one additional custom designed polymorphic marker D1S2633c. The primer sequences for D1S2633c are as follows: D1S2633c_F, 5'-TCTTG GAGCCCTGAGCTG-3'; D1S2633c_R， 5'-AGGCTTAGCCAGAACCTTCC-3'. The heterozygosity indices were 0.71 [D1S2633], 0.86 [D1S2870], and 0.66 [D1S2633c] and the probability of all three markers at the NPHP4 locus being homozygous by chance is one in 72 cases $(1.4 \%)$. Forward primers were tagged at the $5^{\prime}$ end with the following universal tag sequence: 5'-GAGAGAAAGGGAAGGGAG-3' [Yang et al., 2000]. A universal primer, consisting of the same sequence as the added tag, was fluorescently labeled with either 6-FAM ${ }^{\mathrm{TM}}$,
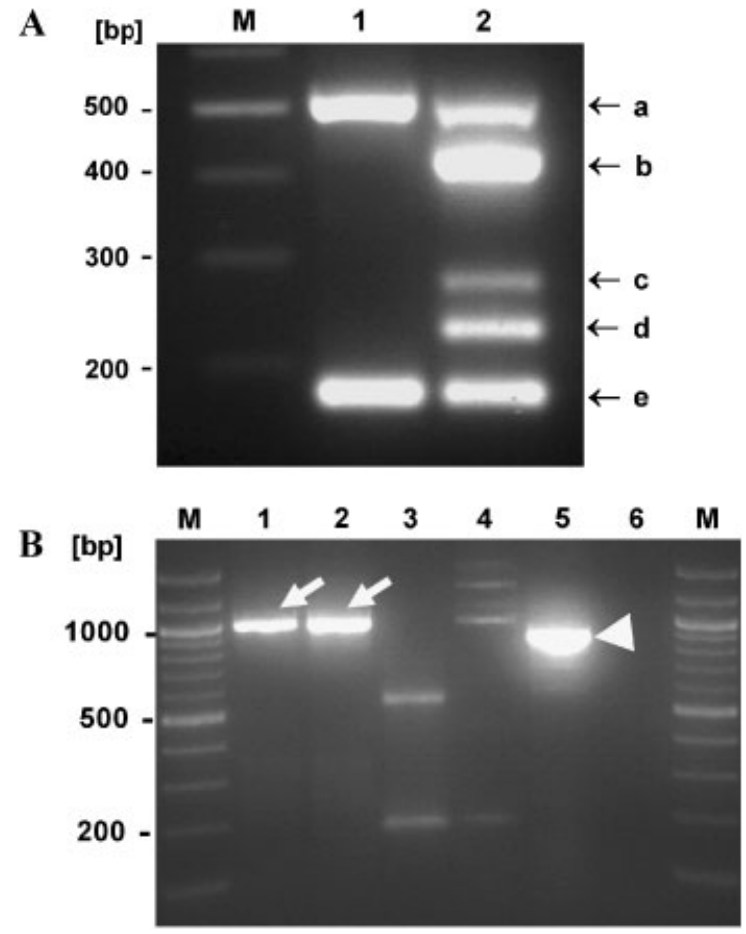

FIGURE 2. A: Detection of homozygous deletions in NPHP1 using a multiplex PCR approach. Agarose-gel electrophoresis of PCR products is shown for a patient (Patient F150) with a homozygous NPHP1 deletion (lane 1) and for a healthy control individual (lane 2). PCR products derived from the NPHP1 deletion region are NPHP1 exon 7 (arrow d, 236 bp), NPHP1 exon 11 (arrow c, $286 \mathrm{bp}$ ), and NPHP1 exon 20 (arrow b, $436 \mathrm{bp}$ ). Positive control markers are derived from gene LHX9 exon 4 (arrow a, $515 \mathrm{bp}$ ) and LHX9 exon 6 (arrow e, $180 \mathrm{bp}$ ) on chromosome 1, which were used to ensure the presence of DNA and accurate PCR amplification. In lane 1, genomic DNA of a patient with NPHP type 1 was used as a PCR template. Note that the PCR products for both control markers (arrows a and $e$ ) are present, whereas products for NPHP1 exons 7, 11, and 20 (arrows b, c, and d, respectively) are absent, indicating a homozygous NPHP1 deletion and confirming the diagnosis NPHP type 1 . In lane 2, note that all five fragments (arrows a-d) were amplified when using genomic DNA of a healthy control individual as a template. Lane M, 100bp ladder DNA size marker (New England Biolabs, Ipswitch, MA). B: Splice effects of NPHP1 mutation c.1027G $>$ A investigated by RT-PCR. RNA (100 ng) of a healthy control individual and a patient (Patient F232) carrying the NPHP1 mutation c.1027G $>$ A, which changes the last nucleotide of exon 9 and a conserved splice donor consensus site, were used as templates for RT-PCR. Control RT-PCR amplification of full-length MAPRE2 cDNA (984 bp) was performed to ensure presence and quality of mutant (lane 1) and wild-type (lane 2) RNA samples (white arrows). RT-PCR amplifications using NPHP1 primers located in exon 8 (forward) and exon 16 (reverse) are shown for the mutant RNA in lane 4 and for the wild-type RNA in lane 5. Note the product of the expected size of $874 \mathrm{bp}$ in the wild-type sample (white arrowhead), which is missing in the mutant sample. Instead, five aberrant products of different sizes are visible, when using mutant RNA as RT-PCR template (lane 4). Genomic DNA $(100 \mathrm{ng})$ was used as a control for the respective primers (MAPRE2, lane 3; NPHP1, lane 6) to test for DNA contamination. Lane M, 100-bp ladder DNA size marker.

$\mathrm{HEX}^{\mathrm{TM}}$, or NED ${ }^{\mathrm{TM}}$ (Applied Biosystems, Foster City, CA). PCR was performed in a total volume of $10 \mu \mathrm{L}$ containing $2 \mathrm{ng}$ of genomic DNA, 2 pmol tagged forward primer, 8 pmol fluorescently labeled universal primer, $10 \mathrm{pmol}$ reverse primer, and $5 \mu \mathrm{L}$ of HotStarTaq DNA polymerase mixture (Qiagen, Hilden, Germany). A touchdown protocol was applied (see next section 
for details). Diluted PCR products were separated on an automated capillary sequencer (Applied Biosystems) and results were analyzed with the help of GeneMarker 1.1 genotyper software (SoftGenetics, State College, PA).

\section{PCR Amplification and Sequencing}

In appropriate patients, exons of NPHP1 (NM_000272.2), NPHP2/INVS (NM_014425.2), NPHP3 (NM_153240.3), NPHP4 (NM_015102.2), or NPHP5/IQCB1 (NM_001023570.1) were individually amplified using exon flanking primers (sequences available upon request). A $10-\mu \mathrm{L}$ PCR reaction was set up with $10 \mathrm{ng}$ genomic DNA, 10 pmol each of forward and reverse primer, and $5 \mu \mathrm{L}$ HotStarTaq Polymerase mixture (Qiagen). DNA amplification was performed on a thermal cycler (Mastercycler; Eppendorf, Hamburg, Germany) using Thermo-Fast $($ 96-well plates (ABgene, Rochester, NY) and applying the same touchdown PCR protocol for amplifying all exons or microsatellite markers. The following touchdown PCR protocol was used: initial denaturation at $94^{\circ} \mathrm{C}$ for $15 \mathrm{~min}$, followed by 20 cycles with an annealing temperature decreasing $0.7^{\circ} \mathrm{C}$ per cycle, starting at $72^{\circ} \mathrm{C}$ for $30 \mathrm{sec}$; denaturation at $94^{\circ} \mathrm{C}$ for $30 \mathrm{sec}$, and extension at $72^{\circ} \mathrm{C}$ for $1 \mathrm{~min}$. An additional 20 cycles were added: $94^{\circ} \mathrm{C}$ for $30 \mathrm{sec}$, $55^{\circ} \mathrm{C}$ for $30 \mathrm{sec}, 72^{\circ} \mathrm{C}$ for $1 \mathrm{~min}$, with a final extension of $72^{\circ} \mathrm{C}$ for $10 \mathrm{~min}$. For mutational screening $2 \mu \mathrm{L}$ were directly used in a CEL I endonuclease digest. For sequencing, PCR products were purified using spin columns according to the manufacturer's instructions (Marligen, Ijamsville, MD) and directly sequenced using the dideoxy chain termination method on an automatic capillary genetic analyzer (Applied Biosystems). Mutation nomenclature follows the checklist for the description of sequence variants (www.hgvs.org/mutnomen/checklist.html). Position +1 corresponds to the A of the ATG translation initiation codon of the respective reference gene sequences.

\section{CEL I Endonuclease Preparation}

Preparation of crude extract containing $30 \mathrm{kDa}$ of single-strandspecific endonuclease CEL I was purified from celery as described [Oleykowski et al., 1998; Till et al., 2003, 2004]. In brief, $0.5 \mathrm{~kg}$ of store-bought celery stalks was juiced at $4^{\circ} \mathrm{C}$, adjusted to $0.1 \mathrm{M}$ Tris-HCl, pH 7.7, $100 \mu \mathrm{M}$ phenylmethylsulphonyl fluoride (PMSF), and spun for $20 \mathrm{~min}$ at $2,600 \mathrm{~g}$ to pellet debris. All following steps were performed at $4{ }^{\circ} \mathrm{C}$. The supernatant was saturated to $25 \%$ with $\left(\mathrm{NH}_{4}\right)_{2} \mathrm{SO}_{4}$, mixed for $30 \mathrm{~min}$, and spun at $16,000 \mathrm{~g}$ for $40 \mathrm{~min}$. The resulting supernatant was saturated to $80 \%\left(\mathrm{NH}_{4}\right)_{2} \mathrm{SO}_{4}$, mixed for $30 \mathrm{~min}$, and spun at $16,000 \mathrm{~g}$ for $90 \mathrm{~min}$. The pellet was suspended in $0.1 \mathrm{M}$ Tris- $\mathrm{HCl}, \mathrm{pH} \mathrm{7.7}$, $100 \mu \mathrm{M}$ PMSF (1/10 starting volume), transferred to a dialysis

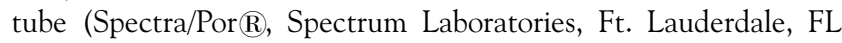
10,000 molecular weight [MW] cutoff), and dialyzed against 321 of the same buffer with four changes over $4 \mathrm{hr}$. Aliquots were stored at $-20^{\circ} \mathrm{C}$.

\section{Heteroduplex Formation and CEL I Treatment}

The CEL I endonuclease enzyme recognizes single-base mismatches present in heteroduplex DNA and cleaves both strands. Heteroduplex DNA was obtained by heat-denaturing $2 \mu \mathrm{L}$ of an exon-PCR amplified patient DNA sample mixed with an equal amount of a healthy control sample (wild type). DNA fragments were denatured at $95^{\circ} \mathrm{C}$ for $10 \mathrm{~min}$ followed by cooling to $85^{\circ} \mathrm{C}$ at a rate of $2^{\circ} \mathrm{C} / \mathrm{sec}$ and a gradual cooling to $25^{\circ} \mathrm{C}$ at a rate of $0.1^{\circ} \mathrm{C} / \mathrm{sec}$ to allow random reannealing of the denatured DNA strands. CEL I treatment of the reannealed samples was performed with $6 \mu \mathrm{L}$ of crude celery extract. The reaction mixture was incubated at $45^{\circ} \mathrm{C}$ for $5 \mathrm{~min}$, put on ice, and stopped by mixing with glycerol-containing (30\%) loading buffer supplemented with EDTA (final concentration $250 \mathrm{mM}$ ) followed by a $1.5 \%$ agarose gel electrophoretic separation of the digested fragments for $1 \mathrm{hr}$ at $150 \mathrm{~V}$. Samples showing aberrant bands were purified and directly sequenced. To test the mutation detection rate (sensitivity) of the heteroduplex-based CEL I digest-method and our custom-made celery extract, we examined 79 different formerly published NPHP 1-5 mutations, and found 73 samples (92\%) showing an aberrant banding pattern after CEL I treatment. Out of 366 patients, CEL I endonuclease mutation analysis was performed for all exons in NPHP1, NPHP3, or NPHP4 in those patients showing uninterrupted coexistent homozygosity for all three microsatellite markers typed within the respective gene region. Altogether, we performed 1,276 exon-PCRs in 54 patients showing homozygosity at the NPHP1 (32), NPHP3 (14), or NPHP4 (8) loci. After heteroduplex formation, CEL I digest, and agarose gel electrophoresis, we identified 59 samples with aberrant banding patterns. After sequencing these samples we identified 17 homo/hemizygous mutations, 34 samples showed known SNPs, and in eight samples no sequence change was observed (false positives).

\section{Reverse-Transcription Polymerase Chain Reaction (RT-PCR) and RNA Preparation}

We extracted total RNA from Epstein-Barr virus (EBV)transformed lymphocytes from a patient (Patient F232) carrying the NPHP1 mutation c.1027G $>\mathrm{A}$ in exon 9 and a control individual using Trizol Reagent (Invitrogen, Carlsbad, CA). We carried out RTPCR using the SuperScript III One-Step RT-PCR System (Invitrogen). For the partial NPHP cDNA amplification of the exon 8-16 fragment $(874 \mathrm{bp})$ the following primers were used: NPHP1_exon8_775_F (5'-CGGGCATCTTCTGTCTTGTTAATCATGT-3') and NPHP_exon16_1645_R (5'-TGAGGCTGCCTTCTCATTGTCATAATCT- $\left.3^{\prime}\right)$. To ensure the presence and quality of the RNA we performed a control RT-PCR using control primers MAPRE2_F (5', CACCATGCCTGGGCCGACCCAAACCCTGTCCCCA-3') and MAPRE2_R to amplify the full length cDNA (984bp) of the MAPRE2 gene. Amplified PCR products were separated on agarose gels by electrophoresis, cut out from the gel, purified, and directly sequenced on an ABI capillary sequencer (Applied Biosystems).

\section{RESULTS Analysis of Homozygous Deletions in NPHP1}

It has been described that homozygous deletions constitute the most frequent cause of NPHP [Konrad et al., 1996]. To detect NPHP1 deletions, we performed a multiplex PCR using exonflanking primers for NPHP1 exons 7, 11, and 20, together with two control primer pairs. We analyzed genomic DNA samples of 470 patients with the presumptive diagnosis of NPHP. Lack of all three NPHP1 exons, and simultaneous presence of both control amplicons was observed in 97 patients (21\%), indicating a homozygous NPHP1 deletion and confirming the diagnosis NPHP1 (Table 1, Figs. 1 and 2A). Eight out of these 97 patients had an association with retinitis pigmentosa (SLS) and eight patients with Cogan oculomotor apraxia. The remaining patients were screened for the presence of NPHP1 point mutations or mutations in other NPHP genes applying a homozygosity preselection approach or direct sequencing (see below).

\section{Preselection for Homozygosity}

We screened for homozygosity due to the observation, that in all NPHP genes, the occurrence of homozygous mutations is 
TABLE 1. Distribution of Recessive NPHPMutations in a Worldwide Cohort of 730 Patients With Nephronophthisis With and Without Extrarenal Manifestations

\begin{tabular}{|c|c|c|c|c|c|c|c|c|}
\hline & $\begin{array}{c}\text { NPHP1 } \\
\text { homozygous } \\
\text { deletion }\end{array}$ & $\begin{array}{c}\text { NPHP1 point } \\
\text { mutation }^{\mathrm{a}}\end{array}$ & $\begin{array}{c}\text { NPHP2 } \\
\text { mutation }\end{array}$ & $\begin{array}{c}\text { NPHP3 } \\
\text { mutation }\end{array}$ & $\begin{array}{c}\text { NPHP4 } \\
\text { mutation }\end{array}$ & $\begin{array}{c}\text { NPHP5 } \\
\text { mutation }\end{array}$ & $\begin{array}{l}\text { No mutation } \\
\text { found }\end{array}$ & Total \\
\hline $\begin{array}{l}\text { Present study (patients investigated) } \\
\text { All patients (730) ever studied in our } \\
\text { laboratory (including present study) } \\
\left.\text { [Reference }^{g}\right]\end{array}$ & $\begin{array}{l}97(470) \\
171(23.4 \%) \\
{[A, B, C]}\end{array}$ & $\begin{array}{l}11(366)^{\mathrm{b}} \\
15(2.1 \%) \\
{[\mathrm{A}, \mathrm{D}]}\end{array}$ & $\begin{array}{l}2(25)^{\mathrm{c}} \\
10(1.4 \%) \\
{[\mathrm{E}, \mathrm{F}]}\end{array}$ & $\begin{array}{l}2(366)^{\mathrm{b}} \\
5(0.7 \%)[\mathrm{G}]\end{array}$ & $\begin{array}{l}4(366)^{b} \\
19(2.6 \%) \\
{[H, I]}\end{array}$ & $\begin{array}{l}5(37)^{\mathrm{d}} \\
26(3.6 \%) \\
{[\mathrm{K}]}\end{array}$ & $\begin{array}{l}349(470) \\
484(66.3 \%)\end{array}$ & $\begin{array}{l}470^{f} \\
730^{f}(100 \%)\end{array}$ \\
\hline $\begin{array}{l}\text { Senior-Løken syndrome } \\
\left.\text { [Reference }{ }^{\mathrm{g}}\right]\end{array}$ & 13 & 1 & $1[\mathrm{~F}]$ & 0 & $3[\mathrm{H}, \mathrm{I}]$ & $26[\mathrm{~K}]$ & 91 & 135 \\
\hline Cogan ocular apraxia [Reference ${ }^{\mathrm{g}}$ ] & $8[\mathrm{D}]$ & $1[\mathrm{D}]$ & 0 & 0 & 0 & 0 & 21 & 30 \\
\hline
\end{tabular}

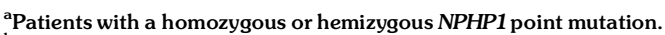

${ }^{\mathrm{b}}$ A total of 366 patients (unrelated families) with NPHP were screened for mutations in NPHP1, NPHP3, and NPHP4 applying a homozygosity screening approach, followed by heteroduplex-based CEL I mutational analysis.

${ }^{c} A$ subset of patients presenting with end-stage renal disease and aged $\leq 5$ years were analyzed for NPHP2/INVS mutations by direct sequencing.

${ }^{\mathrm{d}} \mathrm{A}$ total of 37 out of 71 patients with NPHP and additional eye involvement (retinitis pigmentosa or Leber congenital amaurosis) were screened for NPHP5/IQCB1 mutations by A A total of 37 out of 71 patients with NPHP and additional eye involvement (retinitis pigmentosa or Leber congen
direct sequencing. In 34 cases, sequence analysis was performed earlier and was negative [Otto et al., 2003].

${ }^{e}$ Numbers refer to patients with proven recessive mutations in the respective NPHP genes identified in our laboratory. The percentages refer to the recessive mutations found to date. Note that not all patients underwent a complete screening of all genes and that not all mutations have been published yet.

fOver the last 15 years we ascertained worldwide DNA samples from 730 unrelated families with nephronophthisis, 470 of which were included in the present study. Patients presenting with Joubert syndrome are not part of these cohorts.

${ }^{9}$ References: A, Hildebrandt et al. [1997]; B, Hildebrandt et al. [2001]; C, Heninger et al. [2001]; D, Betz et al. [2000]; E, Otto et al. [2003]; F, O'Toole et al. [2006]; G, Olbrich et al. [2003]; H, Otto et al. [2002]; I, Hoefele et al. [2005]; and K, Otto et al. [2005].

more frequent compared to compound heterozygous mutations. For example, after sequencing all exons of NPHP5 in 92 SLS patients, 14 patients were found to carry a homozygous mutations vs. only two patients with a compound heterozygous mutation [Otto et al., 2005]. We screened 366 patients, in whom we have not found NPHP1 deletions, for homozygosity of three polymorphic microsatellite markers at each of the NPHP1, NPHP3, and NPHP4 loci. In the particular case of the NPHP1 genotype analysis, markers del-5-5(2), del-16, and del-10, known to be located within the known $290-\mathrm{kb}$ deleted region of NPHP1 were used. Out of 366 patients genotyped, 140, 162, and 205 showed homozygosity for markers del-5-5(2), del-16, and del-10, respectively. Combined homozygosity for all three markers was found in 32 patients $(9 \%)$ who were selected for a NPHP1 point mutation analysis (see below). Homozygosity screening to preselect patients in the NPHP3 region was performed by typing microsatellite markers D3S1273, D3S1290, and D3S3713. Homozygosity for these markers was observed in 88, 77, and 42 patients, respectively. A total of eight out of the 366 patients (2\%) showed homozygosity for all three markers at the NPHP3 locus and were for that reason selected for further NPHP3 mutation analysis. Finally, genotyping of microsatellite markers D1S2633, D1S2633c, and D1S2870 at the NPHP4 locus revealed 101, 130, and 86 patients homozygous for the respective markers. Out of 366 patients, $14(4 \%)$ showed coexistent homozygosity for all three markers and were chosen for further NPHP4 mutation analysis.

\section{NPHP1 Point Mutations}

After selection of 32 patients showing homozygosity for three microsatellite markers within the common NPHP1 deleted region, we performed mutational screening for all 20 NPHP 1 exons using heteroduplex based CEL I endonuclease digests in these patients. Agarose gel separations of CEL I digests representing six examples of heteroduplex mismatches representing NPHP 1 point mutations are shown in Fig. 3. Samples showing aberrant banding patterns were sequenced and revealed seven different homozygous/hemizygous NPHP1 point mutations in 11 patients (Tables 1 and 2; Fig. 1). We identified three nonsense mutations (p.R347X, p.Y509X, and p.R586X), two of which were novel findings. The stop mutation p.R586X was recently described as prevalent in Italy [Caridi et al., 2006]. Furthermore, we identified two novel frameshift mutations (p.P186fsX1873 and p.V492fsX513), a novel obligatory splice site mutation (c.1884+1G $>$ A) in intron 18 , and a potential splice mutation (c.1027G $>$ A) in exon 9 (Table 2; Supplementary Fig. S1, available online at http://www.interscience.wiley.com/jpages/1059-7794/suppmat). This mutation was found in five different patients from Germany, accounting for about $3 \%$ of all patients with NPHP1 mutations (Table 1) and was initially described in a patient (F232) with Cogan oculomotor apraxia [Betz et al., 2000]. All five patients from Germany that carried the c. $1027 \mathrm{G}>\mathrm{A}$ mutation share the same homozygous alleles for all three microsatellites typed within the NPHP1 deletion region, indicating a founder effect. Extended genotyping of eight additional microsatellite markers confirm haplotype sharing for at least three families (data not shown). The aforementioned mutation (c. $1027 \mathrm{G}>\mathrm{A}$ ) affects the last nucleotide of exon 9, which is part of the splice donor site and is $80 \%$ conserved in the splice consensus sequence. We tested by RT-PCR for a potential splice effect using RNA of Patient F232, who carries mutation c.1027G $>$ A hemizygously, together with a wild-type control RNA. Splice errors were demonstrated in the mutant RNA (Patient F232) with four splice products of aberrant size and lack of a correctly spliced product. (Fig. 2B). All mutations found, are likely to result in loss-of-function of the NPHP1 gene product. Segregation analysis revealed parental noncontribution in five patients, indicating inheritance of a heterozygous deletion from one parent and transmission of a point mutation from the other parent. In five cases no parental DNA was available to distinguish between homozygous and hemizygous point mutation status (Table 2).

\section{NPHP2 Mutation Analysis in Patients With Early Onset ESRF}

Sequencing of all NPHP2 exons in 25 patients who presented with early onset ESRF by the age of 5 years was performed. We identified two patients with potential loss-of-function mutations (Table 2; Fig. 1; Supplementary Fig. S1). In a family from France (Family A128) we found a compound heterozygous mutation p. $[\mathrm{Q} 485 \mathrm{fs}]+[\mathrm{R} 687 \mathrm{fs}]$. The frameshift mutation p.R687fs is a novel mutation, not described before. Additionally, a homozygous nonsense mutation (p.R899X) was identified in a patient with early onset NPHP and liver fibrosis (Table 2; Supplementary Fig. S1). No mutations were found in six patients presenting with NPHP in combination with a situs inversus phenotype, indicating further heterogeneity in this disease entity. 

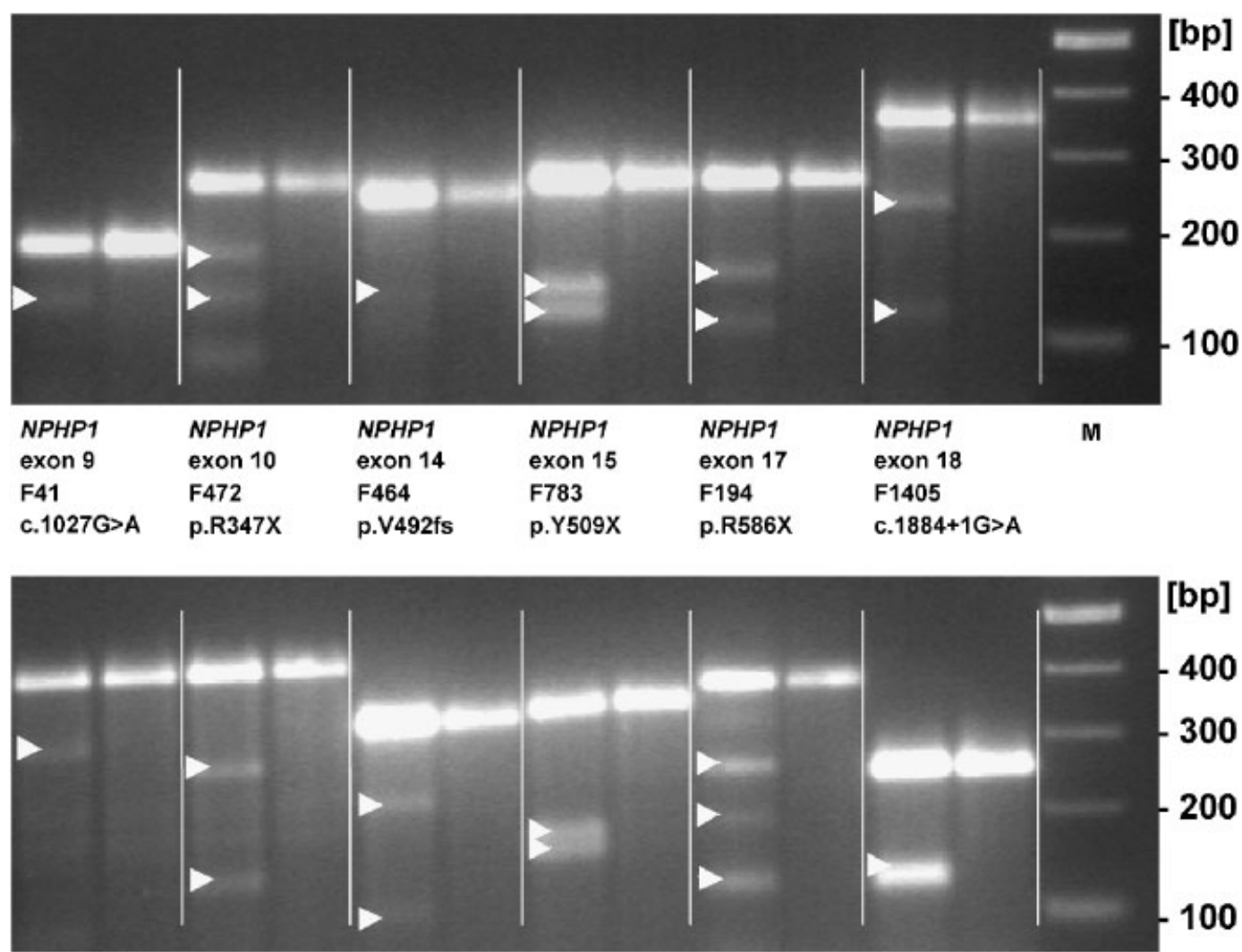

[bp]

$\begin{array}{lllllll}\text { NPHP3 } & \text { NPHP3 } & \text { NPHP4 } & \text { NPHP4 } & \text { NPHP4 } & \text { NPHP4 } & \text { M } \\ \text { exon 26 } & \text { exon 26 } & \text { exon 3 } & \text { exon 18 } & \begin{array}{l}\text { exon 21 } \\ \text { exon 23 }\end{array} & \\ \text { A1125 } & \text { F86 } & \text { F1241 } & \text { F1270 } & \text { F1183 } & \text { F1322 } \\ \text { c.3812+2T>C } & \text { p.R1259X } & \text { p.R59X } & \text { p.E790X } & \text { p.T1004fs } & \text { p.V1091fs }\end{array}$

FIGURE 3. CEL I enzymatic cleavage mutation detection in the NPHP1, -3, and - 4 genes. Mutations in PCR products were identified after performing heteroduplex formation with healthy control DNA, subsequent CEL I endonuclease mismatch digest, and separation on a 1.5\% agarose gel. Mutated samples from patients shown on the left and healthy control samples on the right. Bands resulting from CEL I cleavage are indicated by white arrowheads. Mutated NPHP genes, family numbers, exon numbers, and amino acid changes are shown below lanes. M: 100-bp ladder DNA size marker (New England Biolabs).

\section{NPHP3 Mutation Analysis}

Of 366 patients, eight were found to be homozygous at the NPHP3 locus after genotyping three microsatellite markers. CEL I mutational analysis and subsequent sequencing uncovered two novel homozygous NPHP3 mutations in two patients. CEL I digests of the respective mutated PCR samples are shown in Fig. 3. Both mutations were novel potential loss-of-function mutations and were segregating with the affected status within both families. We identified an obligatory splice donor consensus mutation c. $3812+2 \mathrm{~T}>\mathrm{C}$ in a Turkish family in intron 26, and a nonsense mutation p.R1259X in exon 26 in a family from Italy (Table 2; Fig. 1; Supplementary Fig. S1).

\section{NPHP4 Mutation Analysis}

Following homozygosity mapping at the NPHP4 locus in 366 NPHP patients, 14 patients were selected for CEL I endonuclease mutational analysis of all 30 exons. Sequencing four PCR products showing aberrant banding patterns (Fig. 3) led to the identification of four homozygous NPHP4 mutations (three novel), of which two were frameshift mutations (p.T1004fs and p.V1091fs) and two were nonsense mutations (p.R59X and p.E790X) (Table 2; Fig. 1; Supplementary Fig. S1).

\section{NPHP5 Mutations in SLS Patients}

NPHP5 mutation analysis was performed by direct sequencing of all 16 exons in altogether 37 SLS patients. We identified five patients that carried potential loss of function mutations homozygously (Table 2; Fig. 1; Supplementary Fig. S1). A total of three nonsense mutations (p.W444X, p.R461X, and p.R489X), a 2-bp deletion leading to a frameshift and a premature stop in exon 6 (p.F142fs), and an obligatory splice acceptor site mutation in intron 6 (c.488-1G >A) were found. The mutations p.W444X, p.R489X, and c.488-1G $>A$ are novel findings. Four out of five patients, in whom we found NPHP5 mutations, developed blindness early in life (Leber congenital amaurosis).

\section{DISCUSSION}

By positional cloning we and others have identified eight genes as mutated in NPHP. In order to determine the frequency and character of mutations in the genes coding for NPHP1-5, we screened a large cohort of 470 patients with NPHP, applying a combined mutational analysis approach. We identified 97 (21\%) patients carrying a homozygous NPHP 1 deletion and 11 patients with NPHP1 hemi- or homozygous point mutations. Similar results were reported elsewhere, in which recessive NPHP1 mutations 


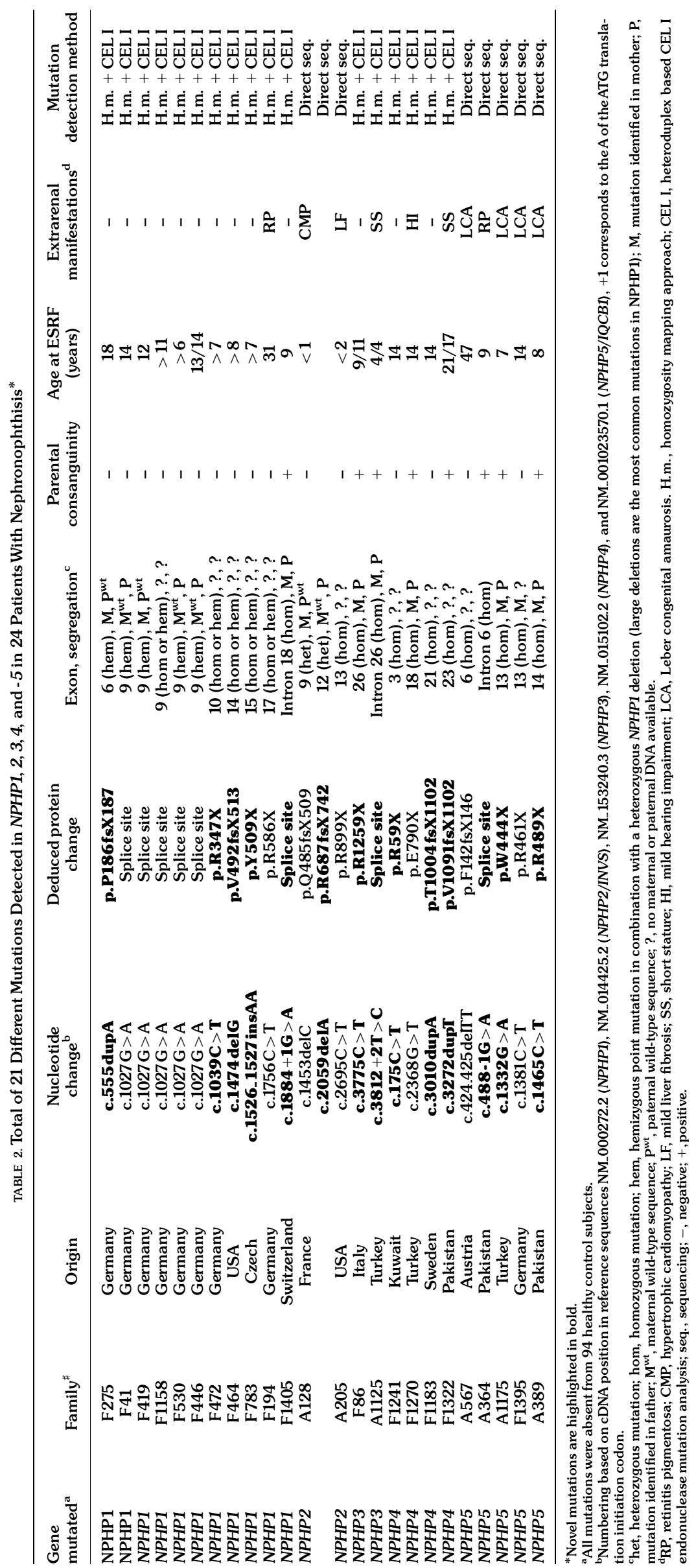


were detected in 94 out of 276 patients (34\%) [Salomon et al., 2003]. Furthermore, we identified recessive mutations in NPHP2, NPHP3, NPHP4, and NPHP5 in 13 additional patients.

Performing mutational analysis in 25 patients who developed ESRF within the first 5 years of life, we identified potential loss-offunction mutations in the NPHP2/INVS gene in two patients, indicating further heterogeneity in early onset patients. In mice, the inversin mouse model (inv/inv) of insertional mutagenesis is associated with renal cysts and cardiovascular defects. Interestingly, one patient carrying an NPHP2 mutation rapidly deteriorated to ESRF at 6 months of age and suffered from a hypertrophic cardiomyopathy due to ventricular septal defects [Otto et al., 2003]. In this study, we did not find NPHP2 mutations in six patients who presented with a situs inversus phenotype, which is consistently seen in inv/inv mice, indicating further heterogeneity in this subset of patients.

In NPHP3, we identified two patients carrying novel homozygous potential loss-of-function mutations. Interestingly, in one of the families with NPHP3 mutations, both affected children developed ESRF at the age of 4 years. Ultrasonography revealed increased echogenicity and medullary cysts on normal sized kidneys in both siblings. The term "adolescent" NPHP for NPHP3 might be questioned and patients presenting with early-onset ESRF should also be considered for NPHP3 diagnostics. The two observed mutations confirm for the first time the initial disease gene identification publication, in which only three patients with recessive mutations were reported [Olbrich et al., 2003].

In NPHP4, we detected two homozygous nonsense and two homozygous frameshift mutations in four patients. The age of onset of ESRF was between 14 and 21 years, which is in the range of formerly published reports. Three out of four mutations were novel findings, adding to the 16 different recessive mutations described earlier [Otto et al., 2002; Hoefele et al., 2005].

In NPHP5, we identified five potential loss-of-function mutations (three nonsense, two frameshift mutations) in five unrelated SLS patients. Notably, as in the initial report of 16 patients, all observed mutations were premature terminating codon mutations [Otto et al., 2005].

In conclusion, recessive mutations in NPHP1, are the most frequent cause in NPHP, accounting for about $25 \%$ of all cases. In contrast, mutations identified in other NPHP genes (NPHP2-5) are comparatively rare, accounting for only about 1 to $3 \%$ of all cases. Interestingly, in about two-thirds of all patients with NPHP, the underlying gene defect is still unknown and we expect an additional scale of genetic heterogeneity for this condition.

Screening a large cohort of 366 patients for 77 exons for NPHP1, NPHP3, and NPHP4 is extremely tedious and costly and would have amounted to 28,182 amplicons to be analyzed. Therefore, we followed a homozygosity mapping strategy based on the observation that recessive mutations in NPHP genes (both alleles mutated) are found to be mostly homozygous, rather than compound heterozygous. For example, direct sequencing of all exons in NPHP4 for 271 patients revealed nine patients with homozygous mutations vs. five patients that carried compound heterozygous mutations [Otto et al., 2002; Hoefele et al., 2005]. We genotyped three highly polymorphic microsatellite markers, positioned in close proximity to each of the respective genes. Theoretically, using three markers with a heterozygosity index of 0.9 each, only one out of 1,000 patient samples will be homozygous for all three markers by chance. This approach is helpful to identify remote consanguinity in these patients who are homozygous in a candidate gene region of interest or at a specific known disease locus. This method does not require DNA of parents or other relatives. We acknowledge that the potential weakness of this method is the lack of the identification of compound heterozygous mutations. This problem can be partially circumvented by typing markers at the respective loci in patients with known mutations to identify related patients with compatible genotypes who carry these mutations in a heterozygous state.

Mutational analysis was performed using CEL I endonuclease heteroduplex mismatch cleaving. As a CEL I source we used custom-made crude celery extract. The sensitivity was $92 \%$, which is comparable to other mutation screening methods. It is important to know that some exonuclease activity is associated with the endonuclease CEL I. Long incubation times might destroy the entire signal and a smear of high background will be the result. In practice, some mismatches will be cut by CEL I only in 2 to $20 \%$, leaving the full-length PCR product untouched and the cut fragments hard to visualize. Moreover, when using an excess of PCR product, CEL I will preferably cut only single strands over both strands. The advantages on the other hand are that CEL I is extremely stable during the purification process, during the storage period at $-20^{\circ} \mathrm{C}$, and during the whole assay. The strength of the CEL I mutation detection assay using celery extract is its simplicity, effectiveness, and inexpensiveness. The combined homozygosity approach and CEL I digests are powerful tools for mutation analysis in the light of increasing disease gene identifications and mutational analysis requests.

\section{ACKNOWLEDGMENTS}

We sincerely thank the affected individuals and their families for participation. We are grateful to the following physicians for contribution of materials and clinical data from patients: $F$. Ozaltin, Ankara (Turkey A1175); D. Weitzel, Wiesbaden (Germany F1395); Seema Hashmi, Karachi (Pakistan A364, A389); C. Rudin, Basel (Switzerland F1405), V. Guigonis, Paris (France A128), M. Linshaw, Boston (USA A205), M. Koyun, Antalya (Turkey A1125), K. Lhotta, Innsbruck (Austria A567), G. Gorman, Baltimore (USA F1322), S. Bakkaloglu, Ankara, (Turkey F1270), D. Mueller-Wiefel, Hamburg (Germany F1241), U. Berg, Stockholm, (Sweden F1183), R. Burghard, Memmingen (Germany F1158), J. Dippel, Frankfurt (Germany F530), T. Seeman, Prague (Czech F783), A. Eddy, Seattle (USA F464), H. Bachmann, Bremen (Germany F472), K. Bonzel, Essen (Germany F446), E. Passarge (Essen F419), O. Mehls, Heidelberg (Germany F275), T. Ziegler, Heidelberg (Germany F194), A. Georgii, Hannover (Germany F41), G.M. Ghiggeri, Genova (Italy F86). This research was supported by grants from the National Institutes of Health (DK069274, DK068306, DK064614 to F.H.) and by a grant from the National Kidney Foundation (NKF) (N004727 to J.F.O.), F.H. is the Frederick G.L. Huetwell Professor and Doris Duke Distinguished Clinical Scientist.

\section{REFERENCES}

Attanasio M, Uhlenhaut HN, Sousa VH, O’Toole JF, Otto E, Anlag K, Klugmann C, Treier A, Helou J, Sayer JA, Seelow D, Nuernberg G, Becker C, Chudley AE, Nuernberg P, Hildebrandt F, Treier M. 2007. Loss of GLIS2 causes nephronophthisis in humans and mice by increased apoptosis and fibrosis. Nat Genet 39:1018-1024.

Betz R, Rensing C, Otto E, Mincheva A, Zehnder D, Lichter P, Hildebrandt F. 2000. Children with ocular motor apraxia type Cogan carry deletions in the gene (NPHP1) for juvenile nephronophthisis. J Pediatr 136:828-831.

Caridi G, Dagnino M, Trivelli A, Emma F, Perfumo F, Ghiggeri GM. 2006. Stop codon at arginine 586 is the prevalent nephronophthisis type 1 mutation in Italy. Nephrol Dial Transplant 21:2301-2303. 
Delous M, Baala L, Salomon R, Laclef C, Vierkotten J, Tory K, Golzio C, Lacoste T, Besse L, Ozilou C, Moutkine I, Hellman NE, Anselme I, Silbermann F, Vesque C, Gerhardt C, Rattenberry E, Wolf MT, Gubler MC, Martinovic J, Encha-Razavi F, Boddaert N, Gonzales M, Macher MA, Nivet H, Champion G, Bertheleme JP, Niaudet P, McDonald F, Hildebrandt F, Johnson CA, Vekemans M, Antignac C, Ruther U, Schneider-Maunoury S, Attie-Bitach T, Saunier S. 2007. The ciliary gene RPGRIP1L is mutated in cerebello-oculo-renal syndrome (Joubert syndrome type B) and Meckel syndrome. Nat Genet 39:875-881.

Heninger E, Otto E, Imm A, Caridi G, Hildebrandt F. 2001. Improved strategy for molecular genetic diagnostics in juvenile nephronophthisis. Am J Kidney Dis 37:1131-1139.

Hildebrandt F, Otto E, Rensing C, Nothwang HG, Vollmer M, Adolphs J, Hanusch H, Brandis M. 1997. A novel gene encoding an SH3 domain protein is mutated in nephronophthisis type 1. Nat Genet 17: 149-153.

Hildebrandt F, Rensing C, Betz R, Sommer U, Birnbaum S, Imm A, Omran $\mathrm{H}$, Leipoldt M, Otto E; Arbeitsgemeinschaft fur Paediatrische Nephrologie (APN) Study Group. 2001. Establishing an algorithm for molecular genetic diagnostics in 127 families with juvenile nephronophthisis. Kidney Int 59:434-445.

Hildebrandt F, Otto E. 2005. Cilia and centrosomes: a unifying pathogenic concept for cystic kidney disease? Nat Rev Genet 6:928-940.

Hoefele J, Sudbrak R, Reinhardt R, Lehrack S, Hennig S, Imm A, Muerb U, Utsch B, Attanasio M, O'Toole JF, Otto E, Hildebrandt F. 2005. Mutational analysis of the NPHP4 gene in 250 patients with nephronophthisis. Hum Mutat 25:411.

Konrad M, Saunier S, Heidet L, Silbermann F, Benessy F, Calado J, Le Paslier D, Broyer M, Gubler MC, Antignac C. 1996. Large homozygous deletions of the $2 \mathrm{q} 13$ region are a major cause of juvenile nephronophthisis. Hum Mol Genet 5:367-371.

Mollet G, Salomon R, Gribouval O, Silbermann F, Bacq D, Landthaler G, Milford D, Nayir A, Rizzoni G, Antignac C, Saunier S. 2002. The gene mutated in juvenile nephronophthisis type 4 encodes a novel protein that interacts with nephrocystin. Nat Genet 32:300-305.

O'Toole JF, Otto EA, Frishberg Y, Hildebrandt F. 2006. Retinitis pigmentosa and renal failure in a patient with mutations in INVS. Nephrol Dial Transplant 21:1989-1991.

Olbrich H, Fliegauf M, Hoefele J, Kispert A, Otto E, Volz A, Wolf MT, Sasmaz G, Trauer U, Reinhardt R, Sudbrak R, Antignac C, Gretz N, Walz G, Schermer B, Benzing T, Hildebrandt F, Omran $H$. 2003. Mutations in a novel gene, NPHP3, cause adolescent nephronophthisis, tapeto-retinal degeneration and hepatic fibrosis. Nat Genet $34: 455-459$.

Oleykowski CA, Bronson Mullins CR, Godwin AK, Yeung AT. 1998. Mutation detection using a novel plant endonuclease. Nucleic Acids Res 26:4597-4602.

Otto E, Betz R, Rensing C, Schatzle S, Kuntzen T, Vetsi T, Imm A, Hildebrandt F. 2000. A deletion distinct from the classical homologous recombination of juvenile nephronophthisis type 1 (NPH1) allows exact molecular definition of deletion breakpoints. Hum Mutat 16:211-223.

Otto E, Hoefele J, Ruf R, Mueller AM, Hiller KS, Wolf MT, Schuermann MJ, Becker A, Birkenhager R, Sudbrak R, Hennies HC, Nurnberg P, Hildebrandt F. 2002. A gene mutated in nephronophthisis and retinitis pigmentosa encodes a novel protein, nephroretinin, conserved in evolution. Am J Hum Genet 71:1161-1167.

Otto EA, Schermer B, Obara T, O’Toole JF, Hiller KS, Mueller AM, Ruf RG, Hoefele J, Beekmann F, Landau D, Foreman JW, Goodship JA, Strachan T, Kispert A, Wolf MT, Gagnadoux MF, Nivet H, Antignac C, Walz G, Drummond IA, Benzing T, Hildebrandt F. 2003. Mutations in INVS encoding inversin cause nephronophthisis type 2, linking renal cystic disease to the function of primary cilia and left-right axis determination. Nat Genet 34:413-420.

Otto EA, Loeys B, Khanna H, Hellemans J, Sudbrak R, Fan S, Muerb U, O’Toole JF, Helou J, Attanasio M, Utsch B, Sayer JA, Lillo C, Jimeno D, Coucke P, De Paepe A, Reinhardt R, Klages S, Tsuda M, Kawakami I, Kusakabe T, Omran H, Imm A, Tippens M, Raymond PA, Hill J, Beales P, He S, Kispert A, Margolis B, Williams DS, Swaroop A, Hildebrandt F. 2005. Nephrocystin-5, a ciliary IQ domain protein, is mutated in SeniorLøken syndrome and interacts with RPGR and calmodulin. Nat Genet 37:282-288.

Salomon R, Mollet G, Gribouval O, Silbermann F, Saunier S, Antignac C. 2003. NPHP1 and NPHP4 mutations in juvenile nephronophthisis. J Am Soc Nephrol 14:SU-FC233.

Saunier S, Calado J, Benessy F, Silbermann F, Heilig R, Weissenbach J, Antignac C. 2000. Characterization of the NPHP1 locus: mutational mechanism involved in deletions in familial juvenile nephronophthisis. Am J Hum Genet 66:778-789.

Saunier S, Salomon R, Antignac C. 2005. Nephronophthisis. Curr Opin Genet Dev 15:324-331.

Sayer JA, Otto EA, O'Toole JF, Nurnberg G, Kennedy MA, Becker C, Hennies HC, Helou J, Attanasio M, Fausett BV, Utsch B, Khanna H, Liu Y, Drummond I, Kawakami I, Kusakabe T, Tsuda M, Ma L, Lee H, Larson RG, Allen SJ, Wilkinson CJ, Nigg EA, Shou C, Lillo C, Williams DS, Hoppe B, Kemper MJ, Neuhaus T, Parisi MA, Glass IA, Petry M, Kispert A, Gloy J, Ganner A, Walz G, Zhu X, Goldman D, Nurnberg P, Swaroop A, Leroux MR, Hildebrandt F. 2006. The centrosomal protein nephrocystin-6 is mutated in Joubert syndrome and activates transcription factor ATF4. Nat Genet 38:674-681.

Till BJ, Colbert T, Tompa R, Enns LC, Codomo CA, Johnson JE, Reynolds SH, Henikoff JG, Greene EA, Steine MN, Comai L, Henikoff S. 2003. High-throughput TILLING for functional genomics. Methods Mol Biol 236:205-220.

Till BJ, Burtner C, Comai L, Henikoff S. 2004. Mismatch cleavage by single-strand specific nucleases. Nucleic Acids Res 32:2632-2641.

Yang X, She C, Guo J, Yu AC, Lu Y, Shi X, Feng G, He L. 2000. A locus for brachydactyly type A-1 maps to chromosome 2q35-q36. Am J Hum Genet 66:892-903. 